\title{
The State of the Cardiovascular System Under the Action of Industrial Electromagnetic Fields
}

\author{
G. V. Gazya ${ }^{1}$, V. V. Eskov², M. A. Filatov ${ }^{2}$, \\ ${ }^{1}$ Federal Science Center Scientific-research Institute for System Studies of the Russian Academy of \\ Sciences, Moscow, Russian Federation \\ ${ }^{2}$ Surgut State University, Surgut, Russian Federation
}

Received: January 14, 2021. Revised: June 25, 2021. Accepted: July 12, 2021. Published: July 15, 2021.

\begin{abstract}
The influence of industrial low-frequency electromagnetic fields on the human body is currently insufficiently studied. However, such fields are quite common in modern automated production, where various electric drives are used, and they significantly affect the quality of human life. This is especially evident in the conditions of the North, where special ecological factors cause significant changes in the systems of regulation of the body's functions. This study examines the influence of such fields on the parameters of the cardiovascular system of female workers in the oil and gas industry in Russia. Four groups of women were studied, differing in age and electromagnetic field exposure. As a result, the effects of influence of the fields were revealed, especially for the older age group.
\end{abstract}

Keywords-Industrial electromagnetic cardiointervals, chaos, Eskov-Zinchenko effect.

\section{INTRODUCTION}

THE influence of industrial electromagnetic fields (EMF) of low frequency and low intensity on the human body is a poorly studied problem of human biophysics and ecology. The study of this problem is especially relevant for workers in the oil and gas sector in the Far North [1-3].

In the North, under the influence of extreme environmental factors (sharp changes in air temperatures, extremely low humidity in rooms in winter, long winters and the influence of polar factors - (cosmic radiation, etc.), significant changes occur in the parameters of various human functions. all it concerns the state of the cardiovascular system (CVS), and various psychiatric disorders (insomnia, lethargy, cognitive impairment, etc.). All of these factors significantly affect the quality and length of human life in the North [3-5].

In our studies, we studied the state of CVS parameters, which is very sensitive to the action of special environmental factors of the North and to the influence of EMF on production. The combination of these two factors also affects changes in CVS parameters. This is what we dedicate our study to in terms of age-related changes in CVS parameters in oil and gas workers. spheres of Russia.

We conducted these studies for two aged groups in order to research the effects of both weak electromagnetic fields, and study possible age-related changes. It should be noted that age-related aspects (the influence of environmental factors, and electromagnetic fields) have been poorly studied in modern biomedicine $[6,12-16]$. Now we are paying special attention to this problem, since the increase in the life expectancy of the visiting population in the North is an important issue of medicine in all countries accessing to the Northern Territories.

\section{OBJeCt AND Methods}

100 women were examined, oil and gas workers, i.e. living and working in the Khanty-Mansiyski Autonomous Okrug Yugra (North of Russia). These 100 people were divided into 4 groups (25 people in each): 1st group - women under 35 years old without the effect of EMF on the body, 2nd group women over 35 years old, without the effect of EMF; Group 3 - women under 35 years old (under the action of EMF) and the 4 th group - over 35 years old (under the action of EMF). All four groups were examined according to 6 CVS parameters (using the patented Elox-01 device) Samples were registered at least 5 minutes, according to the recommendation of the European Association of Cardiology: $\mathrm{x}_{1}$ - SIM - parameter of the state of the sympathetic autonomic nervous system (ANS); $\mathrm{x}_{2}$ - PAR - the state of the parasympathetic ANS; $\mathrm{x}_{3}$ - SSS heart rate parameters; $\mathrm{x}_{4}$ - SDNN - deviation standard for cardiointervals (CI, RR); $\mathrm{x}_{5}$ - IBN - CVS tension index (according to R.M. Baevsky); $\mathrm{x}_{6}-$ parameters of cardiointervals $(\mathrm{msec})$. All these 6 diagnostic features were calculated for each subject (in each group of 25 people) to medians (Me). The obtained samples of $25 \mathrm{Me}$ (for each $\mathrm{x}_{\mathrm{i}}$, in each group) were processed statistically, also up to Me, but for the whole group (of 25 people). Let us explain that in each sample of CI (and other $\mathrm{x}_{\mathrm{i}}$ ) there were at least 300values of $\mathrm{x}_{\mathrm{i}}$.

In other words, this was a sufficient sample of cardio intervals and this data should have been representative. 
However, the calculations of these samples identified a number of problems that were associated with the further use of statistics in such calculations.

As a result, samples were obtained for five parameters $\mathrm{x}_{\mathrm{i}}$ of the entire state vector of the CVS in the form $\mathrm{x}=\mathrm{x}(\mathrm{t})=\left(\mathrm{x}_{1}\right.$, $\left.\mathrm{x}_{2}, \ldots, \mathrm{x}_{6}\right)^{\mathrm{T}}$ in a six-dimensional phase state space (FPS). Further, statistical comparisons were made for each $\mathrm{x}_{\mathrm{i}}(\mathrm{t})$ in paired comparisons of samples of all four groups using the Mann-Whitney test. The summary matrix of all paired comparisons of samples (all xwas calculated $d_{i}$ ), in which the $p$ values were entered. If $\mathrm{p} \geq 0.05$, then these two samples were considered statistically coincident (they could have a common general population). At $\mathrm{p}<0.05$, the samples were considered different, i.e. they do not have a common population.

\section{RESULTS AND DISCUSSIONS}

We note right away that the statistical comparison of all cardio-vascular system's parameters between all four groups of women showed a rather high percentage of statistical coincidences between the samples. In this case, the MannWhitney test for the $\mathrm{i}$-th and $\mathrm{j}$-th samples (for this pair) shows $\mathrm{p}_{\mathrm{ij}} \geq 0.05$. In other words, this pair can have one (common) general population. We emphasize that all $\mathrm{CI}$ samples and other parameters were initially checked for normal distribution. It turned out that $1.5-2 \%$ of samples could show a normal distribution, while for the rest of the samples, we obtained an abnormal one; therefore, nonparametric tests were used to analyze the data obtained (for example, the MannWhitney test).

Initially, we have built a table to calculate $\mathrm{Me}$ medians for the parameters of the cardio intervals. Table 1 with all 25 median cardio intervals for each group is demonstrated. Recall that each such median was obtained from a sample of $300 \mathrm{CI}$ values for each subject.

For each column containing $25 \mathrm{Me}$, their total $\mathrm{Me}^{\mathrm{C}}$ was calculated and a centile estimate was given for each such column $\mathrm{Me}^{\mathrm{C}}$ (their mean values were found for 5\% and for 95\%). While processing this table, we made a pairwise comparison of all 4 samples Me for cardio intervals. As a result, six different pairs were obtained, which showed a very low percentage of statistical differences: $\mathrm{Pi}<0.05$ was less than $50 \%$ of all six comparison pairs. In the issue, we decided to check all the other five comparison pairs for their statistical differences.

Table 1. The results of the final statistical processing of 25 medians of individual (for each of 25 subjects) samples of cardiointervals of four groups of women, not exposed (groups

1,2 ) and exposed (groups 3,4) to industrial low-frequency electromagnetic fields, presented in $\mathrm{Me}, 5 \%$ and $95 \%$ (percentiles)

\begin{tabular}{|c|c|c|c|c|c|c|c|c|c|c|c|c|}
\hline \multirow{3}{*}{$\begin{array}{l}\text { Num } \\
\text { ber }\end{array}$} & \multicolumn{12}{|c|}{ Group } \\
\hline & \multicolumn{3}{|c|}{1} & \multicolumn{3}{|l|}{2} & \multicolumn{3}{|l|}{3} & \multicolumn{3}{|l|}{4} \\
\hline & $\begin{array}{l}M \\
e \\
\end{array}$ & $\begin{array}{l}5 \\
\% \\
\end{array}$ & $\begin{array}{l}95 \\
\% \\
\end{array}$ & Me & $\begin{array}{l}5 \\
\% \\
\end{array}$ & $\begin{array}{l}95 \\
\% \\
\end{array}$ & Me & $\begin{array}{l}5 \\
\% \\
\end{array}$ & $\begin{array}{l}95 \\
\%\end{array}$ & Me & $\begin{array}{l}5 \\
\% \\
\end{array}$ & $\begin{array}{l}95 \\
\%\end{array}$ \\
\hline \multirow{2}{*}{1} & 59 & 54 & 66 & 71 & 65 & 77 & 73 & 67 & 79 & 73 & 64 & 77 \\
\hline & 0 & 0 & 5 & 0 & 0 & 5 & 0 & 0 & 5 & 0 & 5 & 0 \\
\hline \multirow{2}{*}{2} & 78 & 68 & 86 & 83 & 75 & 89 & 74 & 61 & 85 & 83 & 76 & 91 \\
\hline & 0 & 5 & 5 & 0 & 0 & 0 & 0 & 5 & 0 & 0 & 0 & 0 \\
\hline \multirow[b]{2}{*}{3} & 75 & 68 & 84 & 74 & 70 & 81 & 73 & 68 & 79 & 79 & 70 & 84 \\
\hline & 0 & 5 & 0 & 0 & 0 & 0 & 0 & 0 & 0 & 0 & 5 & 0 \\
\hline
\end{tabular}

\begin{tabular}{|c|c|c|c|c|c|c|c|c|c|c|c|c|}
\hline \multirow{2}{*}{4} & 83 & 77 & 92 & 73 & 64 & 82 & 69 & 61 & 81 & 69 & 62 & 75 \\
\hline & 5 & 0 & 0 & 0 & 0 & 0 & 0 & 5 & 5 & 0 & 5 & 0 \\
\hline \multirow{2}{*}{5} & 84 & 74 & 93 & 78 & 69 & 85 & 67 & 57 & 78 & 72 & 64 & 82 \\
\hline & 0 & 5 & 5 & 0 & 5 & 0 & 0 & 0 & 0 & 0 & 0 & 0 \\
\hline \multirow{2}{*}{6} & 74 & 66 & 82 & 86 & 80 & 92 & 72 & 66 & 77 & 10 & 94 & 11 \\
\hline & 0 & 5 & 0 & 0 & 0 & 0 & 0 & 0 & 0 & 50 & 0 & 40 \\
\hline \multirow{2}{*}{7} & 71 & 63 & 78 & 90 & 82 & 94 & 77 & 71 & 83 & 74 & 69 & 77 \\
\hline & 0 & 0 & 0 & 0 & 5 & 0 & 0 & 0 & 0 & 0 & 0 & 0 \\
\hline \multirow{2}{*}{8} & 63 & 57 & 69 & 80 & 74 & 86 & 65 & 59 & 73 & 66 & 60 & 72 \\
\hline & 0 & 0 & 5 & 0 & 5 & 5 & 5 & 0 & 0 & 0 & 0 & 0 \\
\hline \multirow{2}{*}{9} & 63 & 58 & 76 & 83 & 73 & 91 & 76 & 62 & 88 & 80 & 69 & 84 \\
\hline & 0 & 0 & 0 & 0 & 0 & 0 & 0 & 5 & 0 & 0 & 0 & 5 \\
\hline \multirow{2}{*}{10} & 85 & 72 & 99 & 98 & 87 & 10 & 62 & 52 & 68 & 86 & 81 & 90 \\
\hline & 0 & 5 & 0 & 0 & 5 & 70 & 0 & 0 & 5 & 0 & 0 & 5 \\
\hline \multirow{2}{*}{11} & 71 & 60 & 77 & 70 & 58 & 82 & 63 & 57 & 70 & 76 & 71 & 84 \\
\hline & 0 & 5 & 0 & 0 & 0 & 0 & 0 & 5 & 0 & 0 & 0 & 0 \\
\hline \multirow{2}{*}{12} & 87 & 73 & 10 & 66 & 60 & 71 & 67 & 60 & 75 & 70 & 61 & 75 \\
\hline & 0 & 0 & 10 & 0 & 0 & 0 & 0 & 0 & 0 & 5 & 0 & 0 \\
\hline \multirow{2}{*}{13} & 68 & 61 & 75 & 87 & 82 & 93 & 69 & 60 & 79 & 93 & 88 & 98 \\
\hline & 0 & 0 & 0 & 0 & 0 & 0 & 0 & 0 & 0 & 0 & 0 & 0 \\
\hline \multirow{2}{*}{14} & 58 & 52 & 68 & 81 & 69 & 90 & 56 & 52 & 63 & 64 & 56 & 71 \\
\hline & 0 & 0 & 0 & 0 & 0 & 0 & 0 & 0 & 0 & 0 & 5 & 0 \\
\hline \multirow{2}{*}{15} & 79 & 71 & 87 & 95 & 87 & 10 & 72 & 64 & 87 & 76 & 68 & 83 \\
\hline & 0 & 0 & 0 & 0 & 0 & 20 & 0 & 0 & 0 & 0 & 5 & 5 \\
\hline \multirow{2}{*}{16} & 85 & 77 & 94 & 60 & 52 & 68 & 67 & 61 & 73 & 59 & 53 & 64 \\
\hline & 0 & 0 & 0 & 0 & 0 & 0 & 0 & 0 & 0 & 0 & 0 & 0 \\
\hline \multirow{2}{*}{17} & 80 & 65 & 91 & 74 & 64 & 79 & 78 & 68 & 89 & 55 & 52 & 59 \\
\hline & 0 & 5 & 0 & 0 & 0 & 5 & 0 & 0 & 0 & 0 & 0 & 0 \\
\hline \multirow{2}{*}{18} & 72 & 66 & 79 & 66 & 60 & 76 & 62 & 57 & 69 & 61 & 55 & 67 \\
\hline & 0 & 0 & 0 & 0 & 0 & 0 & 0 & 0 & 0 & 5 & 0 & 0 \\
\hline \multirow{2}{*}{19} & 70 & 58 & 81 & 10 & 98 & 10 & 73 & 64 & 79 & 86 & 80 & 93 \\
\hline & 0 & 0 & 0 & 40 & 0 & 95 & 0 & 0 & 5 & 0 & 0 & 0 \\
\hline \multirow{2}{*}{20} & 81 & 73 & 88 & 90 & 77 & 98 & 83 & 77 & 89 & 76 & 67 & 82 \\
\hline & 0 & 0 & 0 & 0 & 5 & 5 & 0 & 0 & 0 & 0 & 5 & 0 \\
\hline \multirow{2}{*}{21} & 73 & 64 & 78 & 88 & 75 & 96 & 10 & 93 & 11 & 71 & 66 & 78 \\
\hline & 0 & 5 & 5 & 0 & 5 & 0 & 50 & 5 & 20 & 0 & 0 & 0 \\
\hline \multirow{2}{*}{22} & 74 & 66 & 80 & 61 & 54 & 72 & 65 & 60 & 71 & 78 & 72 & 82 \\
\hline & 0 & 0 & 0 & 0 & 5 & 0 & 0 & 0 & 0 & 0 & 0 & 5 \\
\hline \multirow{2}{*}{23} & 87 & 80 & 94 & 72 & 65 & 80 & 69 & 63 & 78 & 79 & 73 & 85 \\
\hline & 0 & 0 & 0 & 0 & 0 & 0 & 0 & 0 & 0 & 0 & 0 & 0 \\
\hline & 82 & 69 & 94 & 71 & 62 & 77 & 76 & 69 & 86 & 74 & 71 & 79 \\
\hline 24 & 0 & 0 & 5 & 0 & 5 & 0 & 0 & 5 & 0 & 0 & 0 & 0 \\
\hline 25 & 83 & 77 & 95 & 79 & 75 & 85 & 89 & 81 & 97 & 70 & 66 & 75 \\
\hline 25 & 0 & 0 & 0 & 0 & 0 & 0 & 0 & 0 & 5 & 0 & 0 & 0 \\
\hline & 75 & 59 & 86 & 79 & 62 & 98 & 71 & 61 & 89 & 74 & 58 & 93 \\
\hline $\mathrm{Me}$ & 6 & 7 & 9 & 5 & 5 & 1 & 9 & 2 & 2 & 5 & 5 & 2 \\
\hline
\end{tabular}

Groups 1 and 2 - women not exposed to electromagnetic fields under 35 and over 35, respectively; groups 3 and 4 - women exposed to electromagnetic fields under 35 years old and over 35 years old, respectively.

Groups 1 and 2 - women not exposed to electromagnetic fields under 35 and over 35, respectively; groups 3 and 4 - women exposed to electromagnetic fields under 35 years old and over 35 years old, respectively.

In Table 1 we present a typical result for $\mathrm{CI}$, where for the 1st age group (without EMF) $\mathrm{Me}_{1}{ }^{\mathrm{C}}=756 \mathrm{msec}$; for the 2nd group (without EMF) $\mathrm{Me}_{2}{ }^{\mathrm{C}}=795 \mathrm{msec}$; for the 3rd group $\mathrm{Me}_{3}{ }^{\mathrm{C}}=719 \mathrm{msec}$ (with exposure to EMF) and for the 4th group of women $\mathrm{Me}_{3}{ }^{\mathrm{C}}=745 \mathrm{~ms}$ (with exposure to EMF). From this table 1 it follows that the effect of EMF (in the 3rd and 4th groups) leads to a significant decrease in the median CI. Moreover, the smallest value $\mathrm{Me}_{3}{ }^{\mathrm{C}}=719 \mathrm{msec}$ can be interpreted as a result of the stress factor in the form of a traditional increase in heart rate and a decrease in the value of $\mathrm{CI}$, respectively. Obviously, $\mathrm{Me}=745 \mathrm{msec}$. for the first group, that it is similar to the third, but the 1st group has no weak electromagnetic field. In the third group, the CI values are significantly lower, which is also typical for the 4th group (see Table 1)

In physiology and medicine, this phenomenon is recorded as the action of a stress agent. Stress usually decreases the CI value. In our case, this is a stable reaction, because the 
measurements of the CVS parameters were carried out within the framework of the professional examination, i.e. on a nonworking day. This proves the stability of the reaction to a decrease in the CI values, since the subjects did not work that day and were not exposed to EMF.In other words, the low values of CI medians for Me sample of each $\mathrm{P}$ are caused precisely by the action of weak electromagnetic fields, which sharply reduced the $\mathrm{CI}$ value (from $\mathrm{Me} 1=756 \mathrm{msec}$. To $\mathrm{Me} 3 \mathrm{C}=719 \mathrm{msec}$.). Moreover, the fourth $\mathrm{Me} 4 \mathrm{C}=745 \mathrm{msec}$. did not even approach the value of Mel of the younger age group (Without exposure to weak electromagnetic field). All this proves the real effect of EM field on the parameters of CVS of women - working in the oil and gas industry of Russia.

Let us emphasize that the 4th group (over 35 years old, under the influence of EMF) demonstrates the value of $\mathrm{Me}_{4}{ }^{\mathrm{C}}=$ $745 \mathrm{msec}$, which is less than $\mathrm{Me}_{1}{ }^{\mathrm{C}}$ (for the younger group without EMF). It should be noted that the CI value increases with age (heart rate falls), but our older group (with EMF) does not reach thevalues of the $\mathrm{Me}_{1}{ }^{\mathrm{C}}$ younger group (without EMF). This clearly reflects the state of the CI and the entire CVS.

As a result, we performed similar calculations for all 5 parameters $x_{i}(t)$ and obtained tables for the remaining four $x_{i}$, which are similar to Table 1. In all cases, the women of the third and fourth groups significantly differed in the medians of 25 samples $\mathrm{x}_{1}(\mathrm{t})$ in comparison with women of the first and second groups (without the effect of EMF).

We will not present all four other tables, but present the final results of pairwise comparison of all five $x_{i}(t)$ for all four groups of women. The results of such a pairwise comparison of samples are given in the summary Table 2. Here are the results of calculating the Mann-Whitney test $\mathrm{p}_{\mathrm{ij}}$ for all $\mathrm{i}-\mathrm{x}$ and $\mathrm{j}$-x pairs of all $\mathrm{x}_{\mathrm{i}}(\mathrm{t})$. This is a generalized table for five $\mathrm{x}_{\mathrm{i}}(\mathrm{t})$.

Recall that the samples of 25 Me were compared for each parameter $\mathrm{x}_{\mathrm{i}}(\mathrm{t})$. If $\mathrm{p}_{\mathrm{ij}} \geq 0.05$, then such a pair of samples Me for $\mathrm{x}_{\mathrm{i}}(\mathrm{t})$ can have one common general population. In this case, such a pair may statistically coincide. The general calculation of all Mann-Whitney criteria $\mathrm{p}_{\mathrm{ij}}$ showed that out of all 30 different pairs of comparisons, exactly 13 pairs showed $\mathrm{p}_{\mathrm{ij}} \leq 0.05$. These pairs are statistically different (see Table 2 ).

The other 17 comparison pairs showed $p_{i j} \geq 0.05$, i.e. they can statistically coincide (they can have a common general population). In this case, we represent such a situation as the first type of uncertainty (FTU). For FTU, statistics show predominant coincidences of pairs of samples, which in reality may not be [6-9].

Table 2. Results of pairwise comparison of the mean values of the ranks of the admissible level of significance of the parameters of heart rate variability of the examined groups 1 -

4 using the nonparametric U criterion Mann - Whitney

\begin{tabular}{lcccccc}
\hline Paramet & \multicolumn{7}{c}{ Values of thecriterion $\boldsymbol{p}$ in pairwise comparison } \\
\cline { 2 - 7 } er & $\mathbf{1 ~ - 2}$ & $\mathbf{1 ~ - 3}$ & $\mathbf{1 ~ - 4}$ & $\mathbf{2 ~ - 3}$ & $\mathbf{2 ~ - 4}$ & $\mathbf{3 - 4}$ \\
\hline SIM & 0.052 & $0.045^{*}$ & $0.000^{*}$ & 0.778 & $0.001 *$ & $0.005^{*}$ \\
PAR & 0.304 & 0.793 & $0.000^{*}$ & 0.516 & $0.003 *$ & $0.001^{*}$ \\
SSS & 0.352 & 0.109 & 0.749 & $0.023 *$ & 0.224 & 0.202 \\
SDNN & 0.084 & 0.050 & $0.000^{*}$ & 0.655 & $0.037 *$ & 0.108 \\
IBN & 0.107 & 0.084 & $0.007^{*}$ & 0.808 & $0.001 *$ & $0.007 *$ \\
\hline
\end{tabular}

Women under 35 years old without exposure to EMF sources, 2 - women over 35 years old without exposure to EMF sources, 3 - women under 35 years old under the influence of EMF sources, 4 - women over 35 years old under the influence of EMF sources; $p$ is the achieved level of significance (at the critical level $\mathrm{p}<0.05$ ); * - groups $\mathrm{p}$ statistically belong to different general populations.

Women under 35 years old without exposure to EMF sources, 2 - women over 35 years old without exposure to EMF sources, 3 - women under 35 years old under the influence of EMF sources, 4 - women over 35 years old under the influence of EMF sources; $p$ is the achieved level of significance (at a critical level <0.05); * - the groups statistically belong to different general populations.

First type of uncertainty shows low efficiency of statistics and here other methods of calculating and assessing differences in CVS parameters are needed. One of these methods is the use of artificial neural networks (ANNs). These ANNs can distinguish the sample and then the FTU can be allowed and the samples will differ [2, 14-16].

Application of FTU, i.e. the prevalence of the absence of statistical differences in the samples of CVS parameters in our case is interpreted in two aspects. First, the effect of EMF and age-related changes in CVS parameters are so insignificant that it is difficult for traditional statistics to demonstrate them. On the other hand, statistics really show low efficiency, since ANN solves this problem [2, 10-12].

Application of FTU, i.e. the prevalence of the absence of statistical differences in the samples of CVS parameters in our case is interpreted in two aspects. First, the effect of EMF and age-related changes in CVS parameters are so insignificant that it is difficult for traditional statistics to demonstrate them. On the other hand, statistics really show low efficiency, since ANN solves this problem [2, 10-12].

All physiology and biomedicine have now approached a certain threshold, after which the sensitivity of calculation methods should be increased and new methods for assessing changes in the parameters of not only CVS, but also other life support systems (including brain neural networks) should be created [10-12]. Within the framework of the new theory of chaos-self-organization (TCS), we have now shown the lack of statistical stability of samples of various parameters of the functions of the human body [1-3, 6-19]. This is now referred to as the Eskov-Zinchenko effect (EES) [1-3, 5, 6, 13-16].

This means that any sample of any parameter $x_{1}(t)$ of the functions of the human body can be unique, it is not statistically repeatable (two times in a row). W. Weaver wrote about this more than 70 years ago, but little attention was paid to his work [20]. As a result, we proved the Eskov-Zinchenko effect (EEZ), which in TCS is defined as type 2 uncertainty (lack of statistical stability of the sample $\mathrm{x}_{\mathrm{i}}(\mathrm{t})$ ) $[1-3,5,6,13-$ 19].

In TCS, new methods and models have been developed that ensured the resolution of type 1 uncertainty (see above) and type 2 uncertainty. These new methods and models made it possible to bring biomedecine to a completely new level in assessing the state of various functions of the human body. In TCS, the concept of a pseudo-atttractor (PA) is introduced, 
which allows one to get rid of the second type of ambiguity both in the study of CVS and in the study of the neuromuscular system, in the study of neural networks of the brain and all electrophysiology.

\section{CONCLUSION}

Studies of four different (by age and exposure to EMF) groups of women workers in the oil and gas sector in the North of the Russian Federation have shown that the influence of the environmental factors of the North and the effects of industrial EMF causes statistical differences in the parameters of CVS. Significant changes in the direction of decreasing CI values showed by medians of cardiointervals of two age groups of women in conditions of EMF exposure.

However, further study of the samples of all five CVS parameters showed the presence of the first type of uncertainty. Most of the pairs of comparison of all five parameters showed statistical coincidence according to the Mann-Whitney test (17 pairs out of 30). They showed statistical coincidence of the Me samples. We interpret this as type 1 uncertainty. It can be solved by applying new methods using artificial neural networks. Within the framework of statistics, uncertainties of the 1st and 2nd types cannot be resolved. New TCS methods also open up new opportunities in biomedicine.

\section{REFERENCES}

[1] E. Vasilaki, E. Antonidakis "Medicine Detection with Low Frequency Electromagnetic Signals" // WSEAS Transactions on Biology and Biomedicine, ISSN / EISSN: 1109-9518 / 2224-2902, Volume 17, 2020, Art. \#12, pp. 99-103.

[2] K. Patel, M.F. Blackard, D.A. Pandya, P. Srivastava, M. Gupta, A.S. Pandya "Hyperuricemia and Cardiovascular Implications" // WSEAS Transactions on Biology and Biomedicine, ISSN / E-ISSN: 1109-9518 / 2224-2902, Volume 17, 2020, Art. \#16, pp. 143-148.

[3] R. Ruvalcaba-Ontiveros, H. Esparza-Ponce, A. CarrascoHernandez, C.D. Gomez-Esparza, E. Orrantia-Borunda, J.G. Murillo-Ramirez, A. Duarte-Moller, J.M. OlivaresRamirez "Synthesis of Gold Nanoshells with Plasmon Resonance Tuned to the Infrared Region of the Electromagnetic Spectrum" // WSEAS Transactions on Biology and Biomedicine, ISSN / E-ISSN: 1109-9518 / 2224-2902, Volume 16, 2019, Art. \#4, pp. 29-36.

[4] V. G. Zilov, A. A. Khadartsev, V. V. Eskov and V. M. Eskov, "Experimental Study of Statistical Stability of Cardiointerval Samples". Bulletin of experimental biology and medicine, vol. 164, no. 2, pp. 115-117, 2017. DOI: 10.1007/S10517-017-3937-1.

[5] V. M. Eskov, V. V. Eskov, Y. V. Vochmina, D. V. Gorbunov and L. K. Ilyashenko, "Shannon entropy in the research on stationary regimes and the evolution of complexity". Moscow University Physics Bulletin, vol. 72, no. 3, pp. 309-317, 2017. DOI: $10.3103 / \mathrm{S} 0027134917030067$.

[6] T. V. Gavrilenko, V. M. Es'kov, A. A. Khadartsev, O. I. Khimikova and A. A. Sokolova, "The new methods in gerontology for life expectancy prediction of the indigenous population of Yugra". Advances in Gerontology = Uspekhi Gerontologii, vol. 27, no.1, pp. 30-36, 01 Jan 2014. PMID: 25051755.

[7] A. I. Kolosova, M. A. Filatov, E. V. Maistrenko and L. K. Ilyashenko, "An Analysis of the Attention Indices in Students from Surgut and Samara Oblast from the Standpoint of Stochastics and Chaos". Biophysics, vol. 64, no. 4, pp. 662-666, 2019.

[8] V. M. Eskov, Y. P. Zinchenko, M. A. Filatov and L. K. Ilyashenko, "Glansdorff-prigogine theorem in the description of tremor chaotic dynamics in cold stress". Human Ecology, no. 5, pp. 22-32, 2017.

[9] M. A. Filatov, L. K. Ilyashenko, A. I. Kolosova and S. V. Makeeva Stochastic and chaotic analysis of students' attention parameters of different ecological zones // Human Ecology, vol. 2019, no. 7, pp. 11-16, 2019

[10] O.E.nFilatova, Yu.V.bBashkatova, L.S.nShakirova, M.A.bFilatov "Neural network technologies in system synthesis" // IOP Conf. Series: Materials Science and Engineering $1047 \quad$ (2021) 012099 doi:10.1088/1757899X/1047/1/012099

[11]K. A. Khadartseva, M. A. Filatov and E. G. Melnikova, "The problem of homogenous sampling of cardiovascular system parameters among migrants in the Russian North". Human Ecology, vol. 2020, no. 7, pp. 27-31, 2020.

[12]Y. V. Vokhmina, V. M. Eskov, T. V. Gavrilenko and O. E. Filatova, "Measuring order parameters based on neural network technologies". Measurement techniques, vol. 58, no. 4, pp. 462-466, 2015. DOI: 10.1007/S11018-015$0735-X$

[13] V. M. Eskov and O. E. Filatova, "Problem of identity of functional states in neuronal networks". Biophysics, vol. 48, no. 3, pp. 497-505, 2003.

[14] V. M. Eskov, O. E. Filatova, V. V. Eskov and T. V. Gavrilenko, "The Evolution of the idea homeostasis: Determinism, stochastics, and chaos-self-organization" Biophysics, vol. 62, no.5, pp. 809-820, 2017.

[15] V. M. Eskov, A. B. Gudkov, M. A. Filatov and V. V. Eskov, "Principles of homeostatic regulation of functions in human ecology". Human Ecology, vol. 2019, no. 10, pp. 41-49, 2019.

[16] O. F. Filatova, Y. V. Bashkatova, M. A. Filatov and L. K. Ilyashenko, "Parameter evolution of cardiovascular system in schoolchildren under the conditions of latitudinal displacement". Human Ecology, vol. 2018, no. 4, pp. 30-35, 2018.

[17] V. M. Eskov Models of hierarchical respiratory neuron networks". Neurocomputing, vol. 11, no. 2-4, pp. 203226, 1996. DOI: 10.1016/0925-2312(95)00048-8.

[18] V. M. Eskov, V. V. Eskov, T. V. Gavrilenko and Y. V. Vochmina, "Formalization of the effect of «repetition without repetition» discovered by N. A. Bernshtein". Biophysics, vol. 62, no.1, pp. 143-150, 2017.

[19]V. M. Eskov, "Cyclic respiratory neuron network with subcycles". Neural Network World, vol. 4, no. 4, pp. 403416.

[20] O. E. Filatova, V. M. Eskov and Y. M. Popov, "Computer Identification of the Optimum Stimulus Parameters in 
Neurophysiology". International RNNS/IEEE Symposium on Neuroinformatics and Neurocomputers, pp. 166-172.

[21] V. M. Es'kov and O. E. Filatova, "Respiratory rhythm generation in rats: The importance of inhibition". Neurophysiology, vol. 25, no. 6, pp. 348-353, 1995.

[22] V. M. Eskov, A. E. Bazhenova, U. V. Vochmina, M. A. Filatov and L. K. Ilyashenko, "N. A. Bernstein hypothesis in the description of chaotic dynamics of involuntary movements of person". Russian Journal of Biomechanics, vol. 21, no. 1, pp. 14-23, 2017.

[23] V. M. Eskov, "Evolution of the emergent properties of three types of societies: The basic law of human development". Emergence: Complexity and Organization, vol. 16, no. 2, pp. 107-115, 2014.

[24]W. Weaver, Science and Complexity. Rokfeller Foundation, New York City. American Scientist, 1948.

\section{Creative Commons Attribution License 4.0 (Attribution 4.0 International, CC BY 4.0)}

This article is published under the terms of the Creative Commons Attribution License 4.0

https://creativecommons.org/licenses/by/4.0/deed.en US 